\title{
Saúde organizacional e síndrome de burnout em escolas e hospitais
}

\section{Organizational healthy and syndrome of burnout in schools and hospitals}

\section{Etienne Andrade de Medeiros Dantas*}

Universidade Federal do Rio Grande do Norte - UFRN, Natal, Rio Grande do Norte, Brasil

\section{Livia de Oliveira Borges**}

Universidade Federal de Minas Gerais - UFMG, Belo Horizonte, Minas Gerais, Brasil

\begin{abstract}
RESUMO
Estudou-se a prevalência da síndrome de burnout em instituições hospitalares e escolares em conformidade com a saúde organizacional dessas instituições. A pesquisa empírica foi realizada em três escolas públicas de ensino médio e em três hospitais públicos, sendo um geral, um especializado e outro militar. Contou-se com amostra acidental de 168 participantes. Para avaliação da prevalência da síndrome de burnout, aplicaram-se o Inventário de Burnout de Maslach (MBI) e uma ficha sociodemográfica. Para análise de saúde organizacional, foram realizadas entrevistas semi-estruturadas com pessoas-chave das organizações, utilizando um roteiro baseado nos fatores-componentes do construto. Os resultados corroboram a expectativa de alta prevalência da síndrome de burnout. Entretanto, não se encontraram diferenças de prevalência entre as instituições participantes, embora os participantes das escolas apresentem escores mais elevados no fator de Diminuição da Realização Pessoal. Em relação à variação da saúde organizacional, observou-se uma precária saúde organizacional em todas as instituições pesquisadas. No entanto, considerando a alta prevalência da síndrome de burnout, é adequado assinalar que os resultados corroboram a previsão de que um ambiente de saúde organizacional deficiente amplia a probabilidade de desenvolvimento da síndrome pelos trabalhadores.
\end{abstract}

Palavras-chave: saúde organizacional; síndrome de burnout; escolas; hospitais.

\begin{abstract}
The prevalence syndrome of burnout was studied in schools and hospitals according to these institutions' organizational health. The empirical research was carried out in three public Junior High schools as well as in three public hospitals - general, specialized, and military. Accidental samples from 168 participants were used. In order to evaluate the prevalence syndrome of burnout, the Maslach Burnout Inventory (MBI) and a socio-demographic form were applied. To carry out the analysis of the organizational health, semi-structured interviews with key-persons in such organizations were conducted following an itinerary based on component factors of the
\end{abstract}


construct. The results confirm the expectation of high prevalence syndrome of burnout. Differences of prevalence among the researched institutions were not found, although the participants from the schools show higher scores when the Reduced Personal Accomplishment factor was focused. In relation to variance of the organizational health, it was observed it is precarious in all of the institutions. However, considering the high prevalence syndrome of burnout, it is appropriate to note that the results corroborate the prediction that an environment of poor organizational health increases the likelihood of developing the disease for workers.

Keywords: Organizational health; syndrome of burnout; schools; hospitals.

\section{Introdução}

Após um longo período de crescimento econômico na década de 1970, foi evidente uma nova fase de desaceleração da economia, diante de diferentes problemas, tais como: a queda na taxa de lucro, - esgotamento do padrão taylorista/fordista de produção, a hipertrofia da esfera financeira entre outros, caracterizando uma crise na regulação econômica em vários países capitalistas, sob o modelo designado como Sociedade do Bem-estar. Neste mesmo contexto, seguiu-se um movimento de concentração de capitais, fusões e privatizações de empresas. ${ }^{1}$

A partir da década de 1980, surgiu a reestruturação produtiva, afetando as relações de trabalho ${ }^{2}$ e a gestão organizacional ${ }^{3}$. A fim de garantir a capacidade de competir e sobreviver no mercado, as organizações inovaram frequentemente (SILVA, 2000; LIMA, 2003; LIMA; CASTRO; MACHADO, 2003; QUADROS, 2004), revisando suas estratégias, redefinindo o negócio, adotando novas tecnologias e equipamentos e implantando mudanças na gestão da força de trabalho entre outros aspectos. (CARLEAL, 1997; CARVALHO, 1999; CASTELLS, 1999; BLANCH, 2003).

Ao lado das referidas transformações das organizações e dos questionamentos sobre sua própria concepção, ocorria também a evolução para uma concepção positiva de saúde ${ }^{4}$; evolução esta que tem como um dos marcos de partida a influência do conceito da Organização Mundial de Saúde (OMS), que toma saúde como sinônimo de um "estado completo de bem-estar físico, mental e social, e não meramente a ausência de doença ou enfermidade" (WORLD HEALTH ORGANIZATION, 1948, p. 100). Tais tendências também mudam o conceito de saúde psíquica ou mental, passando este a ser considerado como um processo psicossocial (construção social) e, não mais, como uma característica estável de personalidade (GOFFMAN, 1978; 1987; ALVARO; TORREGROSA; GARRIDO, 1992; ALVARO; PAEZ, 1996; VELHO, 2002).

Tais evoluções, entre outras, demarcaram o contexto epistêmico, no qual se constituiu e se desenvolveu o campo hoje designado de saúde 
mental e trabalho ${ }^{5}$. A construção sociohistórica da organização deste campo epistemológico, e a atividade do sujeito adulto, capaz de tomar iniciativas, e se antecipar, atuando sobre o ambiente, compreendem fenômenos de interdependência dialética. Assumir tal pressuposto epistêmico é corroborar com a concepção de que a síndrome de burnout é de caráter processual. Como será retomado adiante, ela é desenvolvida dinamicamente na relação do indivíduo com o seu ambiente de trabalho. A construção sociohistórica da organização deste campo epistemológico, e a atividade do sujeito adulto, capaz de tomar iniciativas, e se antecipar, atuando sobre o ambiente, compreendem fenômenos de interdependência dialética.

Assumir tal pressuposto epistêmico é corroborar com a concepção de que a síndrome de burnout é de caráter processual. Como será retomado adiante, ela é desenvolvida dinamicamente na relação do indivíduo com o seu ambiente de trabalho.

Assim sendo, faz sentido esperar que o desenvolvimento da síndrome de burnout pelos trabalhadores afete a saúde organizacional, e viceversa, haja vista que tal enfermidade é indicada pelos seguintes aspectos: capacidade de organização como um todo; capacidade de se adaptar e de solucionar problemas; construir uma identidade própria; avaliar adequadamente a realidade na qual está inserido; e manter a harmonia entre seus subsistemas (SCHEIN, 1965; FORDYCE; WEIL, 1971; BENNIS, 1976). Entretanto, explorar tal relação entre fenômenos (síndrome de burnout e saúde organizacional) é uma atividade bastante complexa, porque se tratam de fenômenos em dois diferentes níveis de análise: a individual e a coletiva, respectivamente. Entretanto, explorar tal relação entre fenômenos (síndrome de burnout e saúde organizacional) é uma atividade bastante complexa, porque se tratam de fenômenos em dois diferentes níveis de análise: a individual e a coletiva, respectivamente.

Planejou-se, então, uma pesquisa para explorar a prevalência da síndrome em instituições hospitalares e escolares, em conformidade com a saúde organizacional dessas instituições. Escolheram-se as instituições hospitalares e escolares como o campo da pesquisa, porque a literatura especializada (por exemplo: MASLACH; JACKSON, 1986; CODO, 1999; MASLACH, SCHAUFELI; LEITER, 2001; BORGES et al., 2002; TAMAYO, 2002; BORGES; ARGOLO; BARKER, 2006) sobre a síndrome de burnout aponta endemia entre professores de ensino fundamental e secundário e entre profissionais de saúde.

Perseguir tal objetivo é relevante porque, além de haver um reduzido número de publicações no Brasil relacionado ao tema saúde organizacional, pode contribuir para fundamentar trabalhos preventivos no campo de saúde mental e trabalho, a partir de estratégias organizacionais coletivas. É de reconhecimento consensual a importância de compreender a síndrome de burnout no 
seu contexto de desenvolvimento, no entanto, não se conhecem pesquisas anteriores que apliquem o construto de saúde organizacional para nortear a apreensão de tal contexto.

Em decorrência do objetivo anteriormente anunciado, apresentar-seá a seguir uma síntese da revisão de literatura realizada sobre os construtos focalizados na pesquisa - a saúde organizacional e a síndrome de burnout - para só depois relatar o método utilizado e as análises dos resultados.

\section{Saúde Organizacional}

Segundo Naves e Gomide Jr. (2000), o conceito de saúde organizacional é oriundo de pesquisas macrossistêmicas do comportamento organizacional. Sua incorporação às pesquisas psicológicas é recente, demandando ainda buscar melhor operacionalização conceitual. Gomide Jr. et al. (1999) construiu e validou uma escala sobre a percepção dos empregados a respeito da saúde da organização, levando em consideração o conceito de saúde organizacional como sendo a "capacidade da organização de desenvolver altos níveis de adaptabilidade e flexibilidade às demandas internas e externas, e ainda desenvolver alto grau de integração entre os empregados e suas equipes de trabalho" (p. 43). Essa mesma escala foi revalidada por Gomide Jr. e Fernandes (2008). Em seguida, Nascimento e Gomide Jr. (2008) propuseram a construção e validação de um novo instrumento de medida do construto baseados nas discussões contemporâneas sobre saúde organizacional que levam em consideração outros elementos não considerados anteriormente, como a questão do bem-estar do trabalhador (QUICK, 1999; PETERSON; WILSON, 2002; SHOAF et al., 2004). Tais escalas saem do nível organizacional de análise para o nível individual, pois são escalas para serem respondidas pelos trabalhadores sobre como percebem a saúde organizacional.

O conceito de saúde organizacional surgiu na década de 1960, desenvolvido por Schein (1965) e Bennis (1976). Esses autores caracterizaram o fenômeno a partir de quatro fatores:

1) Adaptabilidade: capacidade da organização em resolver problemas que, por sua vez, depende da flexibilidade, entendida como a liberdade de aprender por meio da experiência, de mudar simultaneamente com as condições internas e externas;

2) Senso de identidade: conhecimento claro da organização sobre o que ela é, quais são suas metas e onde se pretende chegar; 
3) Teste da realidade: capacidade da organização em procurar conhecer, perceber e interpretar corretamente as condições relevantes do ambiente externo e interno para o seu funcionamento;

4) Estado de integração: grau de harmonia e integração entre os subsistemas da organização, a fim de que estejam funcionando de forma alinhada à estratégia geral da organização (SCHEIN, 1965).

Fordyce; Weil (1971) desmembraram esses quatro conceitos em: identidade, orientação, sensibilidade realista, criatividade, flexibilidade, integração e reserva de energia. Segundo estes autores, a saúde organizacional seria um dos determinantes da eficácia e eficiência organizacionais. Por eficiência, designa-se o ciclo contínuo que produz resultados imediatos em lucro, cria possibilidades de armazenamento de energia e, ao longo prazo, conduz ao crescimento e à sobrevivência da organização (KATZ; KAHN, 1976). A noção de eficácia inclui tanto o componente eficiência, quanto as relações que existem das organizações com o ambiente, resultando em maior poder de sobrevivência organizacional e em controle sobre esse ambiente.

Partindo-se desta visão de eficácia, ratifica-se a observação de Bennis (1976), quando diz que as formas tradicionais de avaliação de eficácia organizacional parecem muito rudimentares, uma vez que desconsideram diversos traços relevantes das organizações modernas (adaptabilidade, necessidade de mudanças).

Apesar dos esforços dos autores em definir de forma clara o conceito de saúde organizacional, pode-se encontrar ainda algumas críticas ao mesmo. Segundo Nascimento e Gomide Jr. (2008) gerou-se, por exemplo, certa confusão teórica para temas como efetividade e saúde organizacional. Já Ramos (1989) considera que o termo saúde organizacional é um deslocamento inapropriado de um conceito da ciência da saúde aplicado à teoria organizacional. A aplicação do termo contém uma analogia e pressupõe a compreensão atual de saúde como sinônimo de saúde do trabalhador (WILLIAMS, 1994; WILSON et al., 2004).

Embora tais críticas sejam pertinentes, por chamar atenção aos riscos em assumir tal conceito, optou-se por utilizá-lo como uma forma de superar as inadequações conceituais feitas às noções de capacidade organizacional e de eficiência. Dessa maneira, tal esforço colabora para melhor captar o que Bennis (1976) reclama, em suas tentativas de apreender a eficácia do conceito.

Aplicou-se, então, o conceito de saúde organizacional na presente pesquisa, inserindo-o no contexto de uma abordagem em torno da organização do trabalho, como uma construção sociohistórica; abordagem essa já referida anteriormente. Dessa forma, apesar de existirem muitos outros conceitos sobre a saúde organizacional (MELLO, 1978; COX; HOWARTH, 1990; WILSON et al., 2004) 
adotaram-se os critérios desenvolvidos por Bennis (1976) e Schein (1965), pois segundo Nascimento e Gomide Jr. (2008), são um dos que mais apresentam consistência conceitual entre as considerações atuais de saúde organizacional. Há também autores, como é o caso de Jaffe (1995) que utiliza o termo saúde organizacional para designar o conjunto de pesquisas que abordam os temas identificados comumente como compondo o campo da saúde mental e trabalho. No entanto, não adotaremos este conceito na presente pesquisa.

\section{Síndrome de Burnout}

O termo burnout significa aquilo que deixou de funcionar por absoluta falta de energia: estar esgotado ou queimado de fora para dentro. Nos Estados Unidos, o conceito surgiu para explicar o processo de deterioração que acontecia com os trabalhadores, principalmente profissionais de ajuda ou de serviços humanos. Foi primeiramente mencionado por Freudenberger, em 1974, para descrever o estado físico e mental de jovens e voluntários, atuando em uma clínica de desintoxicação. Observou que, em pouco tempo, esses jovens se sentiam esgotados, facilmente irritados e desenvolviam também uma atitude cínica em relação aos seus pacientes e uma tendência a evitálos (BUENDIA, 1998).

Segundo Gómez de Cádiz et al. (1997), a definição de burnout advém de vários anos de pesquisa empírica, mediante entrevistas, questionários e observações diretas de trabalhadores de variadas profissões. Estes trabalhadores identificaram que os estudos sobre a síndrome passaram por duas fases. A primeira delas, exploratória, descreveu o fenômeno e foi iniciada com os escritos de Freudenberger (concepção clínica) e de Maslach e Jackson (concepção psicossociológica), na década de 1970.

Na concepção clínica, a síndrome ocorria em razão da atividade laboral, porém por características individuais. A concepção psicossociológica, entende a síndrome como uma reação ao estresse crônico na interação do indivíduo com o ambiente de trabalho e suas características sociais (MASLACH; JACKSON, 1986; MASLACH, 1994; MASLACH; LEITER, 1999; MASLACH; SCHAUFELI; LEITER, 2001).

A segunda fase foi a empírica, iniciada por volta dos anos 1980, quando os pesquisadores preocuparam-se principalmente com 0 aspecto quantitativo e de avaliação. Esta fase é também influenciada pelas concepções organizacional e sociohistórica. Segundo BenevidesPereira (2002a), a primeira dessas concepções considera a síndrome de burnout como uma "conseqüência de um desajuste entre as necessidades apresentadas pelo trabalhador e os interesses da instituição" (BENEVIDES-PEREIRA, 2002a, p. 36). A concepção sociohistórica evidencia mais 0 papel da sociedade atual 
(individualista e competitiva) e menos dos fatores pessoais ou institucionais.

Mesmo que, no início dos estudos sobre a síndrome de burnout, houvesse uma polêmica em considerar o fenômeno como unidimensional, identificando-o somente ao componente de exaustão emocional, a idéia mais aceita atualmente é a de Maslach e Jackson (1986), descrevendo a síndrome como processual e multifatorial, identificando três fatores: Exaustão Emocional, Despersonalização e Diminuição da Realização Pessoal.

A Exaustão Emocional é a manifestação da síndrome mais reconhecida na literatura pertinente, além de ser o seu sintoma central. Caracteriza-se por sensação de fadiga, proporcionando o esgotamento energético emocional que, por sua vez, pode incapacitar o indivíduo a progredir no seu trabalho. A fadiga é considerada um importante componente de estresse da síndrome de burnout.

A Despersonalização é a tentativa do indivíduo em distanciar-se dos seus objetos de trabalho, ou seja, é o desenvolvimento de atitudes de insensibilidade e de despreocupação em relação aos outros. O indivíduo acredita que considerar seus objetos de trabalho impessoais, torna-os mais administráveis. Tal distanciamento permite transformar a exaustão emocional vivenciada em respostas de cinismo. A Diminuição da Realização Pessoal consiste na erosão do sentido de efetividade e da autocompetência e/ou autoeficácia (MASLACH; SCHAUFELI; LEITER, 2001).

Em relação às ocupações, focalizadas na presente pesquisa (profissionais de saúde e de educação), constata-se que publicações no âmbito nacional (por exemplo, TAMAYO, 1997; CODO, 1999; AMORIM, 2002; BENEVIDES-PEREIRA, 2002a; BENEVIDES-PEREIRA, 2002b; BENEVIDES-PEREIRA; MORENO-JIMÉNEZ, 2002; BORGES et al., 2002; CARLOTTO, 2002; CARLOTTO, 2005; TAMAYO; ARGOLO; BORGES, 2005; BORGES; ARGOLO; BAKER, 2006) convergem em assinalar a endemia da síndrome de burnout entre tais profissionais.

Sintonizadas com as perspectivas psicossociológicas, as pesquisas sobre a Síndrome de burnout, têm considerado cada vez mais diversos níveis de análise, como institucionais/organizacionais, ocupacionais e macrossociais (conjunturais). Observa-se, por exemplo, que Maslasch e Leiter (1999) tecem considerações sobre a conjuntura do mundo do trabalho em que a incidência da síndrome tem crescido. Gil-Monte (2005) faz o mesmo e, adicionalmente, contextualiza a importância das pesquisas a partir dos marcos legais. Tamayo, Argolo e Borges (2005) desenvolve sua pesquisa dentro dos marcos ocupacionais, à medida que compõem uma amostra com vários profissionais de saúde do SUS e de hospitais em Natal, comparando profissões e instituições. Gianasi (2004) compara a incidência da síndrome por empresas do setor de transporte coletivo urbano de Natal e indaga sobre aspectos conjunturais do setor 
econômico, as quais estariam afetando o desenvolvimento da síndrome.

Barbosa e Guimarães (2005) discutem sobre a síndrome entre gestores da Eletronorte, tendo em vista às transformações ocorridas na época no setor econômico de inserção da empresa.

Finalmente, observa-se que, embora os estudos sobre a síndrome de burnout sejam recentes, datados a partir de 1970, já é uma linha consolidada de pesquisa nos âmbitos nacionais e internacionais. Mas resta muito a investigar sobre o assunto, principalmente quando se estuda a síndrome de burnout, além do ponto de vista individual, em direção a um nível de análise organizacional e ocupacional. Por essas razões, espera-se na presente pesquisa que, se os resultados da mesma assinalam que as organizações conseguem desenvolver estratégias adequadas e saudáveis no seu dia-a-dia de funcionamento, estarão evitando o desenvolvimento da referida síndrome nos seus trabalhadores.

\section{Método}

Tendo em vista a consecução do objetivo geral da presente pesquisa, já enunciado - explorar a prevalência da síndrome de burnout em instituições hospitalares e escolares em conformidade com a saúde organizacional dessas instituições - definiram-se os seguintes objetivos específicos:

- Descrever o contexto organizacional, segundo a variação da saúde organizacional entre as instituições participantes;

- Identificar a prevalência da síndrome de burnout entre os profissionais de saúde e professores das organizações participantes;

- Analisar se as variações de prevalência da síndrome entre os trabalhadores por instituições participantes (três hospitais e três escolas) acompanham a variação da saúde organizacional dessas mesmas instituições.

Além do caráter descritivo, essa pesquisa terá também traços exploratórios, pois que considerando os diferentes níveis de análises dos dois construtos centrais - síndrome de burnout e saúde organizacional - não analisará diretamente as relações entre eles, mas se fundamentará no construto saúde organizacional para sistematizar a análise do contexto organizacional em que se desenvolve a referida síndrome para, a partir de tal exploração, levantar hipóteses sobre as relações entre a prevalência da síndrome e aspectos do contexto organizacional. 


\section{Participantes}

Esta pesquisa foi realizada em três hospitais (dois atendem ao SUS e um presta assistência aos militares e seus dependentes, bem como aos servidores civis da ativa e seus dependentes) e em três escolas públicas de ensino médio, na cidade de Natal. Todas essas organizações são referências na referida cidade no sentido de que contam com uma história consolidada no estado (Rio Grande do Norte). Considerou-se que abordar organizações de dois ramos distintos de serviços fortaleceria o desenvolvimento da pesquisa, permitindo encontrar maior diversidade de saúde organizacional. No entanto, ambos vivem realidades semelhantes no que diz respeito à precariedade, pois passavam por dificuldades e limitações em relação à falta de pessoal e à infra-estrutura básica para prestação dos serviços.

Para avaliação da saúde organizacional, realizaram-se oito entrevistas semi-estruturadas com pessoas-chave das organizações (diretores, coordenador pedagógico e pessoas envolvidas com o setor de recursos humanos), conforme a acessibilidade das organizações pesquisadas: no hospital-escola e hospital especializado, oportunizouse a realização das entrevistas com o diretor e com a pessoa responsável pelo setor de recursos humanos; no hospital militar, entrevistou-se somente o diretor; nas escolas do centro e da zona sul, as entrevistas foram realizadas com a diretora da instituição; e, na escola de Petrópolis, com a coordenadora pedagógica.

Embora as entrevistas tenham sido realizadas com pessoas de cargos diferentes, o roteiro foi o mesmo para todos os cargos, por se tratar de aspectos da organização e não sobre os conteúdos dos cargos.

Tendo em vista o segundo objetivo específico, o desenvolvimento da pesquisa foi planejado com profissionais de saúde, e também da área educacional, das referidas instituições. Entretanto, as características específicas das atividades de trabalho destes profissionais contribuíram para limitar o acesso a eles. Por isso, trabalhou-se com amostra acidental, em que a inclusão dos indivíduos era definida pelo acesso e disponibilidade dos mesmos para participar da pesquisa. Mas, este fato não impediu que se adotassem alguns procedimentos tendo em vista a busca por algum nível de representatividade da amostra. Assim, entre os profissionais de saúde, aplicaram-se questionários aos médicos, enfermeiros, assistentes sociais, nutricionistas, odontólogos, psicólogos e técnicos e auxiliares de enfermagem. Essas profissões escolhidas são as mais numerosas entre os profissionais de saúde nos hospitais natalenses (BORGES et al., 2005). Em outras palavras, a construção da amostra ocorreu de forma que a mesma abarcasse as diversas profissões mais numerosas da região. 
A amostra ficou composta de 168 participantes, sendo que 83 nos hospitais e 85 nas escolas. A maioria dos participantes era do sexo feminino $(57,8 \%)$. Metade dos participantes apresentava de 19 a 36 anos de idade, sendo que as maiores médias encontraram-se nas escolas, variando entre 39,3 e 42,8 anos. A média em relação ao tempo de trabalho também é maior nas escolas $(M=16,17)$, no entanto, a média de tempo de trabalho na instituição é maior nos hospitais $(M=10,05)$, ou seja, os professores das escolas começaram a trabalhar mais cedo do que os profissionais de saúde dos hospitais, mas os primeiros trocaram mais de organização.

Observou-se também que $47 \%$ das pessoas investigadas concluíram ensino superior e $25,0 \%$, além da graduação cursaram uma especialização e $2,4 \%$ o mestrado, sendo estes médicos, enfermeiros, assistentes sociais, nutricionistas, odontólogos, psicólogos e professores. $26,8 \%$ dos participantes não tinham curso superior (técnicos e auxiliares de enfermagem). Com relação ao estado civil, $58,7 \%$ dos profissionais investigados são casados, $29,3 \%$ solteiros, enquanto os outros $12 \%$ estão entre os viúvos, separados e divorciados.

\section{Procedimentos e instrumentos de coleta de dados}

A coleta de dados, que ocorreu durante o primeiro semestre de 2003, consistiu no levantamento de informações que permitiram a avaliação da saúde organizacional e da prevalência da síndrome de burnout.

Para coleta das informações referentes à saúde organizacional foram aplicadas entrevistas semi-estruturadas para cada organização. 0 roteiro das entrevistas considerava as propriedades do construto (PASQUALI, 1999) e que as respostas seriam submetidas à análise de conteúdo temática ou categorial (BARDIN, 1995; MINAYO, 2000). Consideram-se como propriedades do construto saúde organizacional os fatores já mencionados na seção anterior (adaptabilidade, senso de identidade, teste da realidade e estado de integração), que fundamentaram a elaboração do roteiro de entrevista. Portanto, as entrevistas estavam divididas em quatro partes. As dimensões (indicadores) de tais propriedades foi, por sua vez, buscada por meio de análise de conteúdo temática ou categorial (BARDIN, 1995; MINAYO, 2000) das respostas dos participantes, abrangendo as etapas de leitura flutuante, de classificação, de revisão e enxugamento das categorias até a fase final de análise e sínteses dos resultados.

Complementarmente, foram consultados ainda documentos institucionais. Nos hospitais, exceto o hospital militar (que não permitiu acesso a nenhum documento institucional, além da entrevista), foram analisados o manual do funcionário (que contém 
história, missão e visão da organização), os relatórios anuais de atividades desenvolvidas e o planejamento estratégico da organização. Nas escolas, o documento consultado foi o projeto político-pedagógico. A consulta a tais documentos contribuiu para que a análise das entrevistas fosse desenvolvida em conformidade com 0 contexto organizacional.

Para avaliação da prevalência da síndrome de burnout, aplicou-se o MBI (Inventário de Burnout de Maslach) de acordo com as características de acessibilidade aos profissionais em cada organização. Apesar da existência de outros instrumentos validados para aferição da síndrome de burnout (GIL-MONTE; PEIRÓ, 1997; TAMAYO, 2002; GIL-MONTE, 2005), optou-se pela utilização do MBI em virtude de ser um instrumento conhecido internacionalmente e o mais utilizado (GIL-MONTE; PEIRÓ, 1997). O MBI mensura os três fatores proposto por Maslach e Jackson (1986) - Exaustão emocional, Diminuição da Realização Pessoal e Despersonalização -, já referidos anteriormente. O MBI conta com mais de um estudo de validação no Brasil. Na presente pesquisa, tomou-se por base a tradução, adaptação e validação realizada por Tamayo (1997) com amostra brasiliense, posteriormente submetida a teste empírico (TAMAYO; ARGOLO; BORGES, 2005) com amostra natalense. Tal questionário se compõe de 22 itens e utiliza uma escala de frequência, que varia de ' 1 ' (nunca) a '5' (sempre). Aplicou-se também uma ficha sociodemográfica para obter as informações necessárias à descrição da amostra.

\section{Análise dos dados}

\subsection{Saúde organizacional das escolas públicas e dos hospitais}

A análise de conteúdo das entrevistas sobre saúde organizacional proporcionou a identificação dos indicadores (categorias) dos fatores (ou propriedades) de saúde organizacional: adaptabilidade, senso de identidade, teste de realidade e estado de integração (Quadro 1).

Com relação ao fator adaptabilidade, consideraram-se quatro categorias (indicadores). A primeira delas - a possibilidade dos serviços atenderem às diferentes demandas - era mencionada de maneira ambígua e superficial, bem como os entrevistados nas escolas não sabiam ao certo sobre a adequação do currículo e do calendário às peculiaridades locais. Observou-se que a escola do Centro e a escola da Zona Sul são as mais deficitárias neste aspecto. Quanto à segunda categoria - capacidade de resolver problemas - as entrevistas revelaram que predominam decisões centralizadas na direção. Os entrevistados, no geral, conheciam superficialmente a história da gestão da organização, com exceção dos entrevistados da 
Escola da Zona Sul. Sobre a terceira categoria - melhoria constante nos serviços (tanto em relação à criação de novos serviços, quanto ao aumento da qualidade dos existentes) - os entrevistados relataram melhorias como a estruturação do laboratório de informática, cursos extras para os alunos, desenvolvimento de projetos em parcerias com universidades, com exceção da escola do Centro em que, os dois entrevistados não souberam relatar exemplos concretos de criação de novos serviços. A quarta categoria - mudanças que acompanham as condições internas e externas da organização -, ocorria mais em função de determinação de órgãos fiscalizadores (Secretaria Estadual de Educação) do que, da demanda. Os entrevistados da escola da Zona Sul mencionaram menos mudanças deste tipo.

\begin{tabular}{|c|c|c|c|c|c|c|c|}
\hline \multirow[b]{2}{*}{ Fatores } & \multirow[b]{2}{*}{$\begin{array}{c}\text { Categorias (indicadores de saúde } \\
\text { organizacional) }\end{array}$} & \multicolumn{6}{|c|}{$\begin{array}{l}\text { Organizações/Forma de ocorrência do } \\
\text { indicador }\end{array}$} \\
\hline & & 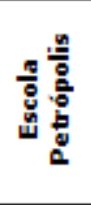 & 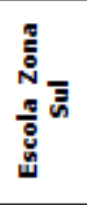 & 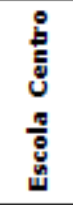 & 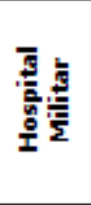 & 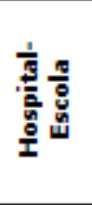 & 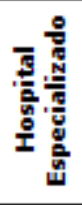 \\
\hline \multirow{4}{*}{$\begin{array}{l}\frac{y}{2} \\
\frac{5}{5} \\
\frac{5}{3} \\
\frac{5}{3}\end{array}$} & $\begin{array}{l}\text { 1. Possibilidade dos serviços atenderem à } \\
\text { diferentes demandas }\end{array}$ & + & + & + & ++ & ++ & ++ \\
\hline & 2. Capacidade de resolver problemas & + & ++ & + & + & + & + \\
\hline & 3. Melhoria constante nos serviços & ++ & ++ & - & ++ & ++ & ++ \\
\hline & $\begin{array}{l}\text { 4. Mudanças que acompanham as condições } \\
\text { internas e externas }\end{array}$ & ++ & + & ++ & ++ & ++ & ++ \\
\hline \multirow{2}{*}{ 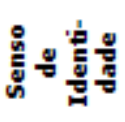 } & 1. Definição do que seja a organização & + & + & + & + & + & + \\
\hline & 2. Clareza das metas organizacionais & + & + & + & + & + & + \\
\hline \multirow{3}{*}{ 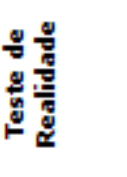 } & 1. Condições do meio ambiente interno & - & - & - & + & + & + \\
\hline & 2. Condições do meio ambiente externo & - & - & - & - & - & - \\
\hline & 3. Avaliação do processo & - & - & - & + & - & - \\
\hline \multirow{7}{*}{ 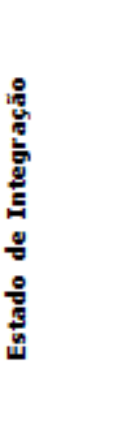 } & 1. Consecução dos objetivos & + & + & + & ++ & - & - \\
\hline & 2. Atuação em conformidade com missão & + & + & + & + & + & + \\
\hline & $\begin{array}{l}\text { 3. Compatibilidade entre qualificação de } \\
\text { pessoal e suas atribuições }\end{array}$ & + & + & + & + & + & + \\
\hline & 4. Canais externos de comunicação & ++ & ++ & ++ & ++ & + & ++ \\
\hline & 5. Canais internos de comunicação & ++ & ++ & ++ & ++ & + & ++ \\
\hline & 6. Distribuição do poder & + & + & + & - & - & - \\
\hline & 7. Qualidade das relações interpessoais & - & + & - & - & + & - \\
\hline
\end{tabular}

Quando se referem à possibilidade dos serviços atenderem às diferentes demandas, os entrevistados nos hospitais referiam-se mais detalhadamente sobre a identificação da demanda e dos serviços 
oferecidos. De modo geral, a adaptabilidade dos hospitais é mais forte do que nas escolas, embora observamos que não existe uma grande diferença entre ambos.

Para avaliar o segundo fator - senso de identidade - consideraram-se duas categorias: conhecimento da organização e de quais sejam seus objetivos e metas organizacionais. Nas entrevistas nas três escolas, essas categorias apareceram de forma superficial, pois que, no geral, os entrevistados revelaram que não tinham um conhecimento detalhado da missão da organização, do que se supõe que consequentemente a transmissão desse conhecimento interna e externamente ocorre de forma deficiente. As metas organizacionais também eram conhecidas insatisfatoriamente, pois os entrevistados pouco conhecem e participam do planejamento da organização. Isto provavelmente afeta negativamente a efetividade organizacional, porque, segundo Jaffe, (1995) a saúde organizacional implica a noção expandida desta efetividade, que envolve, entre outros aspectos, o conhecimento das metas de continuidade.

Nos hospitais, em relação ao segundo fator, a situação é semelhante. Somente os entrevistados do hospital militar relataram planejamento mais sofisticado. No entanto, este é elaborado pela cúpula, sem a participação dos funcionários. É, portanto, um contra-indicador de saúde organizacional.

O terceiro fator - teste de realidade - apresentou-se como o mais deficitário, pois as categorias identificadas na análise apresentavamse predominantemente na forma de sua negação ou falta (condições do ambiente interno e externo e avaliação do processo). Os entrevistados relataram que os recursos materiais das escolas eram mal alocados e as instalações físicas inadequadas, prejudicando a qualidade dos serviços oferecidos. Em relação às condições do ambiente externo, as escolas não conheciam claramente as competências que precisam desenvolver, nem realizavam acompanhamento dos alunos egressos. As avaliações individuais e/ou setoriais (avaliação do processo) praticamente não ocorriam, dificultando as pessoas avaliarem o próprio desempenho.

Nos hospitais, encontraram-se semelhanças em relação às escolas, acerca deste fator. Constatou-se que, nos hospitais, os entrevistados referiam-se a dificuldades de recursos financeiros e de pessoal. A exceção era o hospital militar, onde os entrevistados relataram ter pessoal suficiente para atender a demanda. Quanto ao conhecimento claro das condições do ambiente externo, as condições sanitárias e de higiene da população eram de conhecimento, geralmente, da Secretaria Estadual de Saúde. Com relação à avaliação do processo, encontrou-se um déficit acentuado em relação à presença desta categoria. Somente no hospital militar é que se encontra um processo de avaliação individual sistemático, pois ali existe um plano de carreira sendo aplicado. 
O quarto fator considerado - o estado de integração - abrange o grau de harmonia e integração entre os subsistemas da organização, a fim de que estejam funcionando de forma alinhada à estratégia geral da organização (SCHEIN, 1965). Para a apreensão desse fator, consideram-se sete indicadores: consecução dos objetivos, atuação em conformidade com a missão, compatibilidade entre qualificação de pessoal e suas atribuições, canais externos de comunicação, canais internos de comunicação, distribuição do poder e qualidade das relações interpessoais.

No que diz respeito à consecução dos objetivos, a maioria dos entrevistados nas escolas respondeu que geralmente a organização consegue atingir seus objetivos, embora que contraditoriamente os entrevistados tenham relatado que não sabiam claramente quais eram as metas da organização. Quanto à atuação da organização em conformidade à missão, as respostas indicaram que, geralmente, na escola as ações apresentavam tal conformação. Mas, como as pessoas que atuavam neste tipo de organização têm um conhecimento superficial da missão, inferiu-se que, elas acabam agindo de forma superficial também. Quanto à compatibilidade entre a qualificação de pessoal e suas atribuições, em decorrência das escolas participantes serem públicas e adotarem concurso público, todas as pessoas que trabalham atendem ao requisito legal mínimo de qualificação. No entanto, é questionável a atualização da qualificação das pessoas nos cargos, porque inexiste um programa sistemático de treinamento e desenvolvimento.

Em referência à quarta e à quinta categorias deste fator - canais externo e interno de comunicação - em todas as escolas, os entrevistados mencionaram os dois tipos de canais, pois referiram-se às reuniões da equipe, à caixa de sugestões, ao acesso direto à direção e ao conselho de classe, ou seja, as escolas costumavam ouvir aqueles que se utilizam do seus serviços. Isto fazia com que a escola tivesse feedback de suas limitações e deficiências, no entanto, na maior parte das vezes não tinha autonomia para realizar as mudanças e melhorias. Sobre o indicador de distribuição de poder, pode-se considerar que havia evidências positivas de saúde organizacional em todas as escolas pesquisadas, mas de forma parcial, porque as decisões técnicas são sempre tomadas em coletividade e, em contrapartida, as decisões administrativas restringem-se à direção ou à Secretaria Estadual de Educação. Em relação ao último indicador do fator estado de integração - a qualidade das relações interpessoais - observou a presença deste indicador somente na fala do entrevistado da escola da Zona Sul, o qual relatou haver a existência de um trabalho na escola que visasse à melhoria do mesmo, no entanto, este era assistemático e sem objetivos bem definidos. 
Nos hospitais em relação ao quarto fator, estado de integração, a maioria dos entrevistados negou a consecução das metas. Somente o hospital militar revela a presença positiva dessa categoria. A ocorrência das categorias - atuação em conformidade com a missão, compatibilidade entre a qualificação de pessoal e suas atribuições, comunicação interna e externa - assemelhou-se aos resultados das escolas. Somente os entrevistados do hospital-escola referiram-se à falta de canais de comunicação interna e externa, indicando uma organização sem a cultura de ouvir seus "clientes".

Sobre a distribuição de poder, as entrevistas mostraram que nos hospitais, com exceção do hospital militar, inexistia uma distribuição proporcional entre os cargos diretivos e subordinados. Além disso, as atividades predominantes eram individuais. Quando se trata da qualidade das relações interpessoais, somente o hospital-escola mencionou atividades visando à melhoria da qualidade de vida de seus funcionários. No entanto, a direção não soube especificar qual atividade era realizada.

A partir das análises realizadas anteriormente, concluiu-se que existem muitas semelhanças em relação às categorias de saúde organizacional tanto se comparados os tipos de organizações, quanto se comparados somente as escolas e os hospitais. Em nenhum dos fatores, encontrou-se a ocorrência plena de todas as categorias (Quadro 1). Revelando-se que, quando eram observadas, não estavam plenamente desenvolvidos ou não apresentavam todas as características que a literatura pesquisada considera como um bom indicador de saúde organizacional.

Mas é possível assinalar variação das deficiências apresentadas pelas organizações em separado. Apesar dos indicadores referentes aos fatores senso de identidade e estado de integração aparecer de forma igualitária quanto à sua existência, a escola do Centro apresentou mais deficiências neles. A escola de Petrópolis foi a que apresentou qualitativamente um nível melhor de saúde organizacional, deixando a desejar mais no fator teste de realidade, em que a deficiência é comum para todas as escolas. Entre os hospitais, o mais deficiente foi o hospital-escola, apresentando muitas limitações nos fatores senso de identidade e teste de realidade.

\subsection{Síndrome de burnout segundo a saúde organizacional}

Os escores nos fatores da síndrome de burnout (Exaustão Emocional, Diminuição da Realização Pessoal e Despersonalização) foram estimados pela média dos pontos atribuídos pelos indivíduos a cada item que compõe os fatores. Ao compararem-se tais escores entre si (Tabela 1), observou-se que o fator Exaustão Emocional é o que apresenta média mais elevada $(M=2,60)$, além de apresentar também maior desvio-padrão, demonstrando haver uma maior 
dispersão. Corroborando isto, a Tabela 1, mostra também que nesse fator os escores estão mais distribuídos entre os quatro níveis preestabelecidos (intervalos de escores), sendo também o único fator em que a moda da distribuição está no intervalo de escores de 2 a 3. A tendência de este fator apresentar escores mais elevados repetiuse em vários estudos anteriores (TAMAYO, 1997; BENEVIDESPEREIRA, 2002a; 2002b; TAMAYO; ARGOLO; BORGES, 2005). Ao contrário, o fator Despersonalização é o que apresenta média mais baixa $(M=1,92)$. O menor desvio-padrão encontra-se no fator Diminuição de Realização Pessoal (desvio-padrão=0,61). Nestes dois últimos fatores, há uma maior concentração da distribuição no primeiro intervalo $(x \leq 2)$ e uma menor concentração no último intervalo $(x>4)$, chegando a não haver frequência no fator Despersonalização.

\begin{tabular}{|c|c|c|c|c|c|c|}
\hline \multirow{2}{*}{$\begin{array}{l}\text { Fatores da síndrome } \\
\text { de burnout }\end{array}$} & \multirow{2}{*}{ Média } & \multirow{2}{*}{$\begin{array}{l}\text { Desvio- } \\
\text { padrão }\end{array}$} & \multicolumn{4}{|c|}{ Frequência por intervalo } \\
\hline & & & $x \leq 2$ & $2<x \leq 3$ & $3<x \leq 4$ & $x>4$ \\
\hline Exaustão emocional & 2,60 & 0,86 & 29,2 & 45,8 & 18,5 & 6,5 \\
\hline $\begin{array}{l}\text { Diminuição da realização } \\
\text { pessoal }\end{array}$ & 2,19 & 0,61 & 50,0 & 41,1 & 8,3 & 0,6 \\
\hline Despersonalização & 1,92 & 0,67 & 60,7 & 31,5 & 7,7 & 0,0 \\
\hline
\end{tabular}

Quando são comparados os escores médios nos três fatores da síndrome de burnout por tipo de organização (hospitais versus escolas), observa-se que os participantes da amostra das escolas se percebem com mais Exaustão Emocional, Diminuição de Realização Pessoal e Despersonalização. No entanto, utilizando-se o Teste $t$, constata-se que existe diferença significativa somente em relação ao fator Diminuição de Realização Pessoal ( $t=2,87 ; p=0,005)$, sendo que os participantes das escolas apresentam média mais alta nesse fator $(M=2,31)$ do que aqueles dos hospitais $(M=2,05)$. Este fator refere-se à erosão da efetividade e da autocompetência e à falta de satisfação com as realizações e/ou com os sucessos de si próprio no trabalho, como comentado anteriormente. Nesse ponto, recorda-se que, na análise da saúde organizacional, observaram-se problemas no fator senso de identidade, pois que o conhecimento dos objetivos e metas era superficial indicando reduzida participação no estabelecimento dos mesmos.

As semelhanças entre as três escolas, no que se refere à saúde organizacional, foram acompanhadas também por médias nos fatores da síndrome, que não guardam diferenças estatisticamente significativas entre elas (análise de variância $p>0,05$ ). Ao contrário, 
ao compararmos as médias entre os hospitais, encontraram-se diferenças significativas em relação aos fatores: Exaustão Emocional $(F=8,32$; graus de liberdade $=2 ; p=0,001)$, e Despersonalização $(F=7,18 ;$ grau de liberdade $=2 ; p=0,001)$. Constatou-se (Tabela 2), então, que os participantes do hospital-escola apresentaram média mais alta no fator Exaustão Emocional $(M=2,77)$, indicando que os profissionais dessa organização, provavelmente, tinham um nível de estresse mais elevado do que os profissionais dos outros hospitais. Recorda-se, então, que nas entrevistas foram referidas maiores dificuldades de pessoal justamente neste hospital, em virtude da não realização de concursos públicos, a fim de suprir as necessidades de pessoal necessárias ao bom funcionamento das atividades.

\begin{tabular}{clccc}
\hline $\begin{array}{c}\text { Fatores da } \\
\text { síndrome de } \\
\text { burnout }\end{array}$ & Hospitais & N & Média & $\begin{array}{c}\text { Desvio- } \\
\text { padrão }\end{array}$ \\
\hline Exaustão & Hospital militar & 19 & 2,69 & 0,74 \\
emocional & Hospital-escola & 35 & 2,77 & 0,77 \\
& Hospital especializado & 29 & 2,06 & 0,67 \\
\hline \multirow{2}{*}{ Diminuição de } & Hospital militar & 19 & 2,09 & 0,56 \\
realização pessoal & Hospital-escola & 35 & 2,05 & 0,54 \\
& Hospital especializado & 29 & 2,02 & 0,64 \\
\hline \multirow{2}{*}{ Despersonalização Hospital-escola } & 19 & 2,15 & 0,59 \\
& Hospital militar & 35 & 1,95 & 0,63 \\
& Hospital especializado & 29 & 1,56 & 0,44 \\
\hline
\end{tabular}

Quanto ao fator Despersonalização, a média mais elevada ocorreu no hospital militar $(M=2,15)$. A partir da análise de saúde organizacional, observa-se que nesse hospital, os dirigentes trabalham de forma mais centralizada, fazendo com que os funcionários sintam-se menos participantes dos processos de trabalho. Além disso, não existe a presença de trabalhos que visem à melhoria das relações interpessoais.

Ainda fazendo-se um paralelo com saúde organizacional foi visto que, os profissionais das escolas pesquisadas não eram beneficiados com trabalhos que visem à melhoria dos recursos humanos, como programas de motivação, qualidade de vida no trabalho, etc. E somente na escola da Zona Sul, onde foi relatada a intenção deste tipo de trabalho, não se tinham resultados positivos e as atividades eram realizadas de forma aleatória e isoladas do contexto que os profissionais vivenciavam na escola. Além disso, quando analisamos o fator estado de integração, constatou-se que as escolas não têm programa de treinamento e desenvolvimento, criando um ambiente propício à diminuição da realização pessoal no trabalho. 
Repetindo a ANOVA dos escores no fator Despersonalização por organização hospitalar controlando a faixa etária, as médias apresentaram diferença estatística significativa nos hospitais para os indivíduos com idade menor que 36,5 anos $(F=5,70 ; p=0,006)$. Desta forma, observou-se que as reações de despersonalização a despeito das características organizacionais do hospital militar acentuavam-se entre os mais jovens.

Para análise da prevalência da síndrome de burnout, Maslach e Jackson (1986) recomendam identificar três níveis de intensidade da síndrome em cada fator (baixo, médio e alto) a partir dos percentis da curva normal, estabelecendo os pontos que dividem os indivíduos da amostra em proporções iguais. Entretanto, a identificação de tais percentis na presente amostra não é recomendável porque, além do tamanho pequeno da amostra, levaria aparentar que se teriam proporções proximamente iguais nos três níveis da síndrome (GILMONTE; MARUCCO; 2008). Por isso, utilizaram-se os percentis encontrados na pesquisa de Tamayo, Argolo e Borges (2005), porque se trata de pesquisa realizada na mesma cidade.

A partir dos níveis em cada fator, é hipoteticamente possível identificar 27 combinações distintas. Por meio da aplicação de análise de clusters identificaram-se as combinações ocorridas na amostra, a exemplo do que foi feito por Tamayo, Argolo e Borges (2005) e por Jacques, Borges, Heloani e Cassiolato (2010). Observou-se que: dos 168 profissionais analisados, 60,12\% (101 pessoas) da amostra apresentaram uma configuração mais avançada (escores altos e médios) da síndrome (sendo que das 101 pessoas, 37,62\% estão no nível máximo, no qual convergem escores altos nos três fatores); $19,64 \%$ da amostra (33 pessoas) apresentam uma configuração intermediária de desenvolvimento da síndrome combinando escores altos, médios e baixos; e, finalmente $20,23 \%$ (34 pessoas) apresentam uma configuração iniciante de desenvolvimento da síndrome, combinando apenas escores médios e baixos. Tais resultados corroboraram a existência de elevada prevalência da síndrome entre os participantes da amostra.

Levantou-se, então, a frequência das configurações da síndrome por tipo de organizações (Tabela 3) e constataram-se pequenas diferenças, cuja casualidade não é eliminada pelo teste estatístico aplicado (Qui-quadrado=0,213 para $p=0,90$ ). Tal ausência de diferença é coerente com as observações sobre o contexto organizacional, pois que, embora que as organizações tivessem atividades muito diferentes, assemelhavam-se em apresentar no geral precária saúde organizacional. 


\begin{tabular}{|c|c|c|}
\hline \multirow{2}{*}{$\begin{array}{l}\text { Configurações dos fatores da } \\
\text { síndrome de burnout }\end{array}$} & \multicolumn{2}{|c|}{ Tipo de Organização } \\
\hline & Escolas & Hospitais \\
\hline $\begin{array}{l}\text { Síndrome avançada (escores } \\
\text { médios e altos) }\end{array}$ & $51,50 \%$ & $48,50 \%$ \\
\hline $\begin{array}{l}\text { Síndrome intermediária (escores } \\
\text { altos, médios e baixos) }\end{array}$ & $51,50 \%$ & $48,50 \%$ \\
\hline e médios) & $47,10 \%$ & $52,90 \%$ \\
\hline $\begin{array}{l}\text { Qui-Quadrado } \\
\text { (coeficiente de Pearson) }\end{array}$ & \multicolumn{2}{|c|}{$\begin{array}{l}\text { Qui-quadrado }=0,213 \text { para } \\
p=0,90\end{array}$} \\
\hline
\end{tabular}

Entre as escolas, observou-se que a maior frequência da configuração avançada da síndrome de burnout, encontrava-se na escola da Zona Sul $(25,7 \%)$; e, entre os hospitais, no hospital-escola $(23,8 \%)$. No hospital especializado ocorria justamente o contrário, ou seja, parte dos seus profissionais encontrava-se no nível mais distante de apresentar a síndrome $(35,3 \%)$, diminuindo a frequência nos níveis mais elevados de incidência da síndrome. $\mathrm{Na}$ escola do Centro e na escola de Petrópolis, as maiores frequências ocorriam no segundo tipo; enquanto, na escola da Zona Sul, no primeiro tipo.

\section{Considerações finais}

O primeiro objetivo específico da presente pesquisa - Descrever o contexto organizacional, segundo a variação da saúde organizacional entre as instituições participantes - foi plenamente atingido, mostrando que a estratégia de analisar as entrevistas de pessoaschave das instituições foi viável para tal objetivo. No entanto, diferente do que se esperava, a diversidade de condições de saúde organizacional foi limitada, talvez pelo fato de todas as organizações pesquisadas tratar-se de ramos de atividades muito similares: todas são prestadoras de serviços básicos e públicos. Dessa forma, elucidaram-se mais semelhanças que diferenças. Isso significa que a opção por dois ramos de serviços foi insuficiente. Todas as instituições participantes apresentam uma saúde organizacional com várias deficiências ou precariedades. No entanto, é importante destacar que algumas diferenças foram encontradas: havia mais fraqueza de senso de identidade e estado de integração nas escolas e, entre elas, na escola do Centro; entre os hospitais, o hospitalescola apresentou-se mais deficiente quanto ao senso de identidade e teste de realidade, enquanto o hospital militar apresentou um problema específico no que se refere ao fator estado de integração em decorrência da estrutura de poder centralizada, no entanto 
apresentou outros indicadores positivos em relação ao mesmo fator como avaliar atingir adequadamente os objetivos estabelecidos.

As escolas participantes eram mais homogêneas: todas de ensino médio, administradas pela Secretaria Estadual de Educação, enquanto que os hospitais apresentavam características organizacionais diferentes: dois eram federais, mas um vinculava-se simultaneamente ao Ministério da Educação e ao Ministério da Saúde, mediados pela UFRN; outro, militar e o terceiro, filantrópico.

Quanto ao segundo objetivo específico - identificar a prevalência da síndrome de burnout entre os profissionais de saúde e professores das diferentes organizações participantes - foi plenamente atingido e os resultados corroboraram a expectativa de alta prevalência, alimentada pelas pesquisas anteriores (LAUTERT, 1997; BORGES et al, 2002; CARLOTTO, 2002). Entretanto, não se encontraram diferenças de prevalência entre as instituições. Mas encontraram-se diferenças significativas entre as médias de escores nos fatores da síndrome quando se comparam estas por tipo de organização (escolas versus hospitais) em que os professores de ensino médio apresentam mais Diminuição da Realização Pessoal que os profissionais de saúde. E considerando apenas os profissionais de saúde, aqueles que trabalham no hospital-escola apresentam mais Exaustão Emocional e aqueles do hospital-militar, mais Despersonalização.

Quanto ao terceiro objetivo específico - analisar se as variações de prevalência da síndrome entre os trabalhadores por instituições participantes (três hospitais e três escolas) acompanham a variação da saúde organizacional dessas mesmas instituições - foi atingido parcialmente. A variação de prevalência da síndrome entre as instituições participantes foi pequena. Tal variação só era significativa quando se compararam os escores de cada fator. A variação da saúde organizacional também foi reduzida, predominando uma precária saúde organizacional em todas as instituições estudadas. Estes dois resultados deixaram pouca margem para realização da análise planejada. Entretanto, considerando a alta prevalência da síndrome, é adequado assinalar que os resultados corroboram a previsão de que um ambiente de saúde organizacional deficiente amplia a probabilidade de desenvolvimento da síndrome pelos trabalhadores. Além disso, observou-se que as diferenças de saúde organizacional encontradas entre as instituições participantes (ainda que poucas) ocorreram na mesma direção que as diferenças significativas de escores nos fatores da síndrome de burnout:

- Os escores no fator Diminuição da Realização Pessoal foram mais elevados nas escolas quando comparados aos escores dos participantes dos hospitais e tal diferença acompanhou os problemas de saúde organizacional referentes ao senso de identidade que nas 
entrevistas das pessoas-chave das escolas foram mais evidenciados que pelas pessoas-chaves entrevistadas nos hospitais.

- Entre os hospitais, os trabalhadores do hospital-escola apresentaram média mais elevada no fator Exaustão Emocional e foi neste hospital que se sabia haver maiores dificuldades de pessoal devido às carências do quadro no período (sem haver concursos), que é um indicador desfavorável do fator teste da realidade.

- Entre os hospitais, os trabalhadores do hospital militar apresentaram médias mais elevadas em Despersonalização e, na análise sobre saúde organizacional, as entrevistas indicaram haver mais centralização do exercício do poder e, por consequência, menos participação no processo decisório. Além disso, no hospital militar não havia menção a atividades para melhoria das relações interpessoais.

As limitações encontradas para a consecução dos objetivos específicos, já comentadas, obviamente afetaram a consecução do objetivo principal: explorar a prevalência da síndrome em organizações hospitalares e escolares em conformidade com a saúde organizacional dessas instituições. Apesar de tais limitações, avalia-se que a tentativa de atingir tal objetivo permitiu levantar três possíveis relações entre a apresentação dos sintomas da síndrome e os aspectos da saúde organizacional, oferecendo pistas no combate à prevalência da síndrome no nível organizacional. Assim, os resultados sugeriram primeiramente uma relação entre o fator Diminuição da Realização Pessoal e o senso de identidade organizacional no tocante à identificação dos objetivos. Tal associação permite sugerir que programas que desenvolvam um maior envolvimento dos trabalhadores com os objetivos organizacionais, clareando a relação do desempenho profissional com a consecução dos objetivos, podem contribuir para prevenir o desenvolvimento indesejável de tal fator da síndrome. Em segundo lugar, os resultados sugeriram relação entre o fator de Exaustão Emocional e o provimento de pessoal. Tal associação sustenta sugerir que a adoção de políticas de redução de quadros não podem ser implantadas sem um minuciosa avaliação da distribuição de atividades entre os trabalhadores e de seus impactos. Tais cuidados organizacionais se constituíram em uma tática de prevenção ao desenvolvimento indesejável de Exaustão Emocional. Por fim, os resultados sugeriram a existência de uma relação entre o fator de Despersonalização e centralização do poder. Tal associação sustenta que programas de democratização do processo decisório podem contribuir na prevenção do desenvolvimento indesejável de Despersonalização.

As limitações fazem sugerir a replicação da pesquisa com organizações de um maior número de ramos da economia e abrangendo o setor privado, além do público, poderá tornar mais clara à relação da síndrome com o contexto organizacional. De qualquer forma, os resultados encontrados são bastante relevantes 
no planejamento da prevenção à prevalência da síndrome e significam que as organizações têm como contribuir para prevenir a ocorrência da síndrome, promovendo a saúde organizacional. Finalmente, espera-se que este estudo seja visto como uma exploração inicial do assunto, evitando transferir ou aplicar seus resultados para outras realidades.

Finalmente, espera-se que este estudo seja visto como uma exploração inicial do assunto, evitando transferir ou aplicar seus resultados para outras realidades.

\section{Referências}

ALALUF, M. Concepciones del trabajo, estrategias de empleo y evolución de la clase obrera. In: LAHIRE, B.; ROLLE, P.; SAUNIER, P. Lo que el trabajo esconde. Madrid: traficantes de sueños, bifurcaciones, 2005, p. 213-230.

ALVARO, J. L.; PÁEZ, D. Psicología Social de la salud mental. In: ALVARO, J. L.; GARRIDO, A.; TORREGROSA, J. R. Psicología social aplicada. Madrid: Mc-Graw Hill/Interamericana de España, 1996, p. 381-406.

ALVARO, J. L.; GARRIDO, A.; TORREGROSA, J. R. Estructura Social y Salud Mental. In: ALVARO, J. L.; TORREGROSA, J. R.; GARRIDO, A. I nfluencias sociales en la salud mental. Madrid: Siglo Veintiuno de España Editores, 1992, p. 9-30.

AMORIM, C. Síndrome de burnout em fisioterapeutas e acadêmicos de fisioterapia. Um estudo preliminar. In: BENEVIDES-PEREIRA, A. M. $T$. Burnout: quando o trabalho ameaça o bem-estar do trabalhador. São Paulo: Casa do psicólogo, 2002, p. 93-104.

ANTUNES, R. Os sentidos do trabalho: ensaio sobre a afirmação e negação do trabalho. São Paulo: Bontempo, 1999.

Adeus ao trabalho? Ensaio sobre as metamorfoses da centralidade do mundo do trabalho. São Paulo: Cortez; Campinas: Ed. da Universidade de Campinas, 1995.

BARBOSA, S. C.; BORGES, L. O. Saúde mental dos operadores de petróleo sob o turno fixo: os operadores de petróleo de Alto Rodrigues e Mossoró. In: BARBOSA, S. C.; BORGES, L. Os aspectos psicossociais do trabalho dos petroleiros. Natal: EDUFRN, 2007, p. 187-220.

BARBOSA, R. M. A.; GUIMARÃES, T. A. Síndrome de burnout: relações com comprometimento organizacional afetivo entre gestores de organização estatal. Revista de Administração Mackenzie, São Paulo, v. 6, n. 1, p. 157-180, 2005.

BARDIN, L. Análise de conteúdo. Lisboa: Portugal Edições 70, 1995. 
BASTOS, A. V. B.; LOIOLA, E.; QUEIROZ, N.; SILVA, T. D. Conceito e perspectivas de estudo das organizações. In: ZANELLI, J. C.; BORGES-ANDRADE, J. E.; BASTOS, A. V. B. (Orgs.). Psicologia, organizações e trabalho no Brasil. Porto Alegre: Artmed, 2004, p. 63-90.

BAUM, A.; POSLUSZNY, D. M. Health Psychology: Mapping behavioral contributions to healthy and illness. Annual review of psychology, Palo Alto, v. 50, n. 1, p. 137-163, 1999.

BENEVIDES-PEREIRA, A. M. T. As atividades de enfermagem em hospital: um fator de vulnerabilidade ao burnout. In: BENEVIDESPEREIRA, A. M. T. (Org.). Burnout: Quando o trabalho ameaça o bem-estar do trabalhador. São Paulo: Casa do Psicólogo, 2002a, p. 133-156.

O adoecer dos que se dedicam à cura das doenças. O burnout em um grupo de médicos. In: BENEVIDES-PEREIRA, A. M. T. (Org.). Burnout: Quando o trabalho ameaça o bem-estar do trabalhador. São Paulo: Casa do Psicólogo, 2002b, p, 105-132.

BENEVIDES-PEREIRA, A. M. T.; MORENO-JIMÉNEZ, B. O burnout em um grupo de psicólogos brasileiros. In BENEVIDES-PEREIRA, A. M. T. Burnout: Quando o trabalho ameaça o bem-estar do trabalhador. São Paulo: Casa do psicólogo, 2002, p. 157-186.

BENAVIDES, F. G.; GARCíA, A. M.; RUIZ-FRUTOS, C. La salud y sus determinantes. In: BENAVIDES, F. G.; GARCÍA, A. M.; RUIZ-FRUTOS, C. Salud laboral. Conceptos y técnicas para la prevención de riesgos laborales, Barcelona, Masson, 2004, p. 37-48.

BENNIS, W.G. Organizações em Mudanças. São Paulo: Atlas, 1976.

BLANCH, J. En busca del paradigma laboral perdido. In: BLANCH, J. (Org.). Teoría de las relaciones laborales. Desafios. Barcelona: Editorial UOC, 2003, p. 172-194.

BORGES, L. O.; BARBOSA, S. C.; CHAVES, S. S. S.; ANDRADE, P. R. La constituición del campo de salud mental y trabajo en Brasil: avances, contradicciones y límite. In: IX CONGRESO ESPAÑOL DE SOCIOLOGíA, 2007, Barcelona. Anais... Madrid: Federación Española de Sociología, 2004, 1, CD-ROM.

BORGES, L. O.; ARGOLO, J. C.; BAKER, M. C. S. Os valores organizacionais e a síndrome de burnout: dois momentos em uma maternidade pública. Psicologia: Reflexão e Crítica, Porto Alegre, v. 19, n. 1, p. 34-43, 2006.

BORGES, L. O.; ARGOLO, J. C.; PEREIRA, A. L. S.; MACHADO, E. A. P.; SILVA, W. S. A síndrome de burnout e os valores organizacionais: um estudo comparativo em hospitais universitários. Psicologia: Reflexão e Crítica, Porto Alegre, v. 15, n. 1, p.189-200, 2002. BORGES, L. O.; SILVA, V. F.; MARANHÃO, J.; MOURA, H. B.; GÊ, P. C. S. Concepção, planejamento e desenvolvimento da pesquisa. In: 
BORGES, L. O. (Org.), Os profissionais de saúde e seu trabalho. São Paulo: Casa do Psicólogo, 2005, p. 25-46.

BÜCHER, J. S. N. F. Psicologia da saúde no contexto da saúde pública: uma complexidade crescente. In: YAMAMOTTO, O. H.; GOUVEIA, V. V. (Org.). Construindo a psicologia brasileira: desafios da ciência e prática psicológica. São Paulo: Casa do Psicólogo, 2003, p. 213-237.

BUENDíA, J. Estrés laboral y salud. Madrid: Biblioteca Nueva, 1998.

CARLEIAL, L. M. F. Firmas, flexibilidades e direitos no Brasil? Para onde vamos? Revista São Paulo em Perspectiva, São Paulo, v. 11, n. 1, p. 22-31, 1997.

CARLOTTO, M. S. Síndrome de burnout e a satisfação no trabalho um estudo com professores universitários. In: BENEVIDES-PEREIRA, A. M. T. Burnout: quando o trabalho ameaça o bem-estar do trabalhador. São Paulo: Casa do Psicólogo, 2002, p. 187-212.

Síndrome de burnout em instituições particulares de ensino. 2005. Tese (Doutorado de Psicologia Social) - Facultad de Psicología, Universidade de Santiago de Compostela, Santiago de Compostela.

CARVALHO, A. V. Aprendizagem organizacional em tempos de mudanças. São Paulo: Pioneira, 1999.

CASTELLS, M. A sociedade em rede. São Paulo: Paz e Terra, 1999.

CASTILLO, J. J. Sociología del trabajo. Un proyecto docente. Madrid: Siglo XXI de España Editores, 1999.

Tecnos, 1998.

La búsqueda del trabajo perdido. Madrid: Editorial

CLEGG, S. R.; HARDY, C.; NORD, W. R. Handbook de estudos organizacionais (Organizadores da edição brasileira: CALDAS, M.; FACHIN, R.; FISCHER, T.) São Paulo: Atlas, 1998.

CODO, W. Educação: carinho e trabalho. Petrópolis: Vozes, 1999.

CODO, W.; SORATTO, L.; MENEZES, I. V. Saúde Mental e Trabalho. In: ZANELLI, J. C.; BORGES-ANDRADE, J. E.; BASTOS, A. V. B. (Org.). Psicologia, Organizações e Trabalho. Porto Alegre: Artmed, 2004, p. 276-299.

CORIAT, B. Pensar al revés. Trabajo y organización en la empresa japonesa. Madrid: Siglo Veintiuno de España Editores, 1993.

COX, T.; HOWARTH, S. Organizational health, culture and helping. Work and Stress, London, v. 4, n. 2, p. 107-110, 1990.

FORDYCE, J. K.; WEIL, R. Managing with People: A Managers Handbook of Organization Development Methods. Reading: AddisonWesley Publishing Company, 1971.

GIANASI, L. B. S. As fontes de desgaste físico e emocional e a síndrome de burnout no setor de transporte coletivo de Natal. 2004. Dissertação (Mestrado em Psicologia) - Programa de Pós- 
graduação em Psicologia - Centro de Ciências Humanas, Letras e Artes, Universidade Federal do Rio Grande do Norte, Natal.

GIL-MONTE, P. R. El síndrome de quemarse por el trabajo (burnout). Una enfermedad laboral en la sociedad del bienestar. Madrid: Pirámide, 2005.

GIL-MONTE, P. R.; MARUCCO, M. Prevalencia del "síndrome de quemarse por el trabajo" (burnout) en pediatras de hospitales generales. Revista de Saúde Pública, São Paulo, v. 42, n. 3, p. 450-456, 2008.

GIL-MONTE, P. R.; PEIRÓ, J. M. Desgaste psíquico en el trabajo. El síndrome de quemarse. Madrid: Ed. Síntesis, 1997.

GOFFMAN, E. Sintomas mentais e ordem pública. In: FIGUEIRA, S. A. (Org.). Sociedade e doença mental. Rio de Janeiro Campus, 1978, p. 9-18.

GOFFMAN, E. Manicômios, prisões e conventos. Tradução de D. M. LEITE. São Paulo: Perspectivas, 1987.

GÓMEZ DE CÁDIZ, B. T.; SAN JUAN, C.; RIVERO, A. M.; HERCE, C.; ACHUCARRO, C. Burnout profesional ¿Un problema nuevo? Reflexiones sobre El concepto y su evaluación. Revista de Psicología del Trabajo y de las Organizaciones, Madrid, v. 13, n. 1, p. 23-50, 1997.

GOMIDE JR, S.; MOURA, O. I.; CUNHA, W. B.; SOUSA, W. M. V. Explorando o conceito de saúde organizacional: construção e validação de um instrumento de medida para o ambiente brasileiro. In: XXIX REUNIÃO ANUAL DE PSICOLOGIA, Ribeirão Preto. Resumos... Ribeirão Preto: SOCIEDADE BRASILEIRA DE PSICOLOGIA, 1999, v. único, p. 43.

GOMIDE JR., S.; FERNANDES, M. N. Saúde Organizacional. IN: SIQUEIRA, M. M. M. Medidas do comportamento organizacional: ferramentas para diagnóstico e gestão. Porto Alegre: Artmed, 2008. GORZ, A. Adeus ao proletariado. Rio de Janeiro: Forense, 1982. . (Org. ). Crítica da divisão do trabalho. São Paulo: Martins Fontes, 1980, p. 21-141.

Métamorphoses du Travail. Quéte du sens. Critique de la raison économique. Paris: Galilée, 1991.

GUIMARÃES, T. A.; MEDEIROS, J. J. A nova administração pública e a gestão de competências: mudança e flexibilidade organizacional. In: LIMA, S. M. V., Mudança organizacional: teoria e gestão. Rio de J aneiro: FGV, 2003, p. 243-266.

HELOANI, J. R. Organização do trabalho e administração: uma visão multidisciplinar. São Paulo: Cortez, 1996.

J ACQUES, M. G. C.; BORGES, L. O.; HELOANI, J. R.; CASSIOLATO, R. Saúde/doença no trabalho do psicólogo: a syndrome de burnout. In: BASTOS, A. V. B.; GONDIM, S. M. G. (Orgs.). o trabalho do psicólogo no Brasil. Porto Alegre: Artmed, 2010, p. 338-358. 
JAFFE, D. T. The healthy company: research paradigms for personal and organizational health. In: SAUTER, S.; MURPHY, L. R. (Org.). Organization risk factors for job stress. Washington: American Psychological Association, 1995, p. 13-39.

KATZ, D.; KAHN, R. Psicologia social das organizações. São Paulo: Atlas, 1976.

LAUTERT, L. O desgaste profissional: estudo empírico com enfermeiras que trabalham em hospitais. Revista Gaúcha de Enfermagem, Porto Alegre, v. 18, n. 2, p. 133-144, 1997.

LEITE, M. P. O futuro do trabalho: novas tecnologias e subjetividade operária. São Paulo: Página Aberta, 1994.

LIMA, E. A. A pesquisa em saúde mental e trabalho. In: TAMAYO, A; BORGES-ANDRADE, J. E.; CODO, W. (Org.). Trabalho, organizações e cultura. São Paulo: Cooperativa de Editores, 1996, p. 27-35.

LIMA, S. M. V. Mudança organizacional: uma introdução. In: LIMA, S. M. V. (Org.). Mudança organizacional: teoria e gestão. Rio de Janeiro: FGV, 2003, p. 17-64.

LIMA, S. M. V.; CASTRO, A. M. G.; MACHADO, M. S. Trabalhando em parcerias e alianças estratégicas: lições para a gestão de mudanças. In: LIMA, S. M. V. (Org.). Mudança organizacional: teoria e gestão. Rio de Janeiro: FGV, 2003, p. 219-242.

MASLACH, C. Stress, burnout and workaholism. In: KILBURG, R.; NATHAN, P. E.; THORESON, R. W. (Org.). Professionals in distress: issues, syndromes, and solutions in psychology. Washington: American Psychological Association, 1994, p. 53-75. MASLACH, C.; JACKSON, S. Maslach Burnout Inventory Manual. Palo Alto: Consulting Psychologist Press, 1986.

MASLACH, C.; LEITER, M. P. Trabalho: fonte de prazer ou desgaste? Tradução de M. S. Martins. Campinas: Papirus, 1999.

MASLACH, C.; SCHAUFELI, W. B.; LETTER, M. Job burnout. Annual Review of Psychology, Palo Alto, v. 52, n. 1, p. 397-422, 2001.

MATTOSO, J. A desordem no trabalho. São Paulo: Página Aberta, 1995.

MELLO, F. A. F. Desenvolvimento das Organizações: uma opção integradora. Rio de J aneiro: Livros Técnicos e Científicos, 1978.

MINAYO, M. C. S. O desafio do conhecimento. Pesquisa qualitativa em saúde. São Paulo: Hucitec; Rio de Janeiro: ABRASCO, 2000.

NAVES, M. M., GOMIDE-JUNIOR, S. Variáveis macro e microssistêmicas como antecedentes de critérios de eficácia organizacional. Revista da Sociedade de Psicologia do Triângulo Mineiro, Uberlândia, v. 3, n. 4, p. 19-25, 2000.

NASCIMENTO, J. O.; GOMIDE JR, S. Percepções de saúde e efetividade organizacionais: construção, validação e discriminação das medidas dos constructos [Texto completo]. In: VIII Encontro 
Interno. XII Seminário de Iniciação Científica, 2008, Uberlândia. Anais... Uberlândia: Universidade Federal de Uberlândia, v. 1, 2008. OGDEN, J. Psicologia da saúde. Lisboa: CLIMEPSI Editores, 1999. OLIVEIRA, F. Os direitos do anti-valor: a economia política da hegemonia imperfeita. Petrópolis: Vozes, 1998.

PASQUALI, L. Testes referentes a construto: teoria e modelo de construção. In: PASQUALI, L. (Org.). I nstrumentos psicológicos: manual prático de elaboração. Brasília: LabPAM, IBAPP, 1999.

PETERSON, M.; WILSON, J. F. The culture-work-health model and work stress. American J ournal of Behavior, Oak Ridge, v. 26, n. 1, p. 16-24, 2002.

PILATI, R. O comprometimento do trabalhador e a mudança organizacional. In: LIMA, S. M. V. (Org.). Mudança organizacional: teoria e gestão. Rio de J aneiro: FGV, 2003, p. 267-290.

QUADROS, D. R. Empowerment - Aspectos essenciais na valorização do empregado. In: LANER, A. S.; CRUZ JUNIOR, J. B. (Orgs.). Repensando as organizações. Florianópolis: Fundação Boiteux, 2004, p. 455-484.

QUICK, J. C. Occupational Health Psychology: historical roots and future directions. Health Psychology, Washington v. 18, n. 1, p.8288, 1999.

RAMOS, A. G. A nova ciência das organizações. $2^{a}$ edição. Rio de Janeiro: Fundação Getúlio Vargas, 1989.

RANSOME, $P$. The work paradigm: theoretical investigation of concepts of work. Aldershot: Avebury, 1996.

SATO, L.; LACAZ, F. A. C.; BERNARDO, M. H. Psicologia e saúde do trabalhador: práticas e investigações na Saúde Pública de São Paulo.

Estudos de Psicologia, Natal, v. 11, n. 3, p. 281-288, 2006.

SELIGMAN, M. E. P.; CSIKSZENTMIHALYI, M. Positive Psychology An Introduction. American Psychologist, Washington, v. 55, p. 514, 2000.

SCHEIN, E. H. Organizational Psychology, Englewood Cliffs: Prentice Hall, 1965.

SHOAF, C.; GENAIDY, A.; KARWOWSKI, W.; HUANG, S. H. I mproving performance and quality of working life: a model for organizational health assessment in emerging enterprises. Human Factors and Ergonomics in Manufacturing, Roboken, v. 14, n. 1, p. 81-95, 2004.

SILVA, E. I. Motivação no trabalho: Novos tempos, velhas fórmulas. 2000. Monografia (Especialização em Psicologia) Programa de Pós-graduação em Psicologia - Centro de Ciências Humanas, Letras e Artes, Universidade Federal do Rio Grande do Norte, Natal.

STROEBE, W.; STROEBE, M. S. Psicologia Social e Saúde. Tradução C. Nogueira. Lisboa: Instituto Piaget, 1999.

TAMAYO, A. Cultura e saúde nas organizações. Porto Alegre: Artmed, 2004. 
TAMAYO, M. R. Relação entre a síndrome de burnout e os valores organizacionais no pessoal de enfermagem de dois hospitais públicos. 1997. Dissertação (Mestrado em Psicologia) Programa de Pós-Graduação em Psicologia, Instituto de Psicologia, Universidade de Brasília, Brasília.

Burnout: relações com a afetividade negativa, o coping no trabalho e a percepção de suporte organizacional 2002. 2002. Tese (Doutorado em Psicologia) - Programa de Pósgraduação em Psicologia, Instituto de Psicologia, Universidade de Brasília, Brasília.

TAMAYO, M. R., ARGOLO, J. C. T., BORGES, L. O. Burnout em profissionais de saúde: um estudo com trabalhadores do município de Natal. In: BORGES, L. O. (Org.). Os profissionais de saúde e seu trabalho. São Paulo: Casa do psicólogo; Natal: EDUFRN, 2005, p. 223-246.

TONI, M. Visões sobre o trabalho em transformação. Sociologias, Porto Alegre, v. 5, n. 9, p. 246-286, 2003.

TUMOLO, P. S. Trabalho, vida social e capital na virada do milênio: apontamentos de interpretação. Educação \& Sociedade, Campinas, v. 24, n. 82, p. 159-178, 2003.

VELHO, G. Becker, Goffman e Antropologia no Brasil. Sociologia, problemas e práticas, Lisboa cidade, v. 38, p. 9-17, 2002.

WILLIAMS, S. Ways creating healthy work organizations. In: COOPER, C. L. WILLIAMS, S. (Org.). Creating healthy work organization. Chichester: Wiley, 1994, p. 7-24.

WILSON, M. G.; DEJOY, D. M.; VANDENBERG, R. J.; RICHARDSON, H. A.; MCGRATH, A. L. Work characteristics and employee health and well-being: test of a model of healthy work organization. J ournal of Occupational and Organizational Psychology, Leichester, v. 77, n. 4, p. 565-588, 2004.

WORLD HEALTH ORGANIZATION. Preamble to the constitution of the world health organization. In: Official records of the world health organization, n. 2, p. 100, 1948. Disponível em: <http:// policy. who.int/cgibin/om_isapi. dll/infobase $=$ Basicdoc\&softpage $=$ Brow se_Frame_Pg42>. Acesso em: 19 set. 2002.

\section{Endereço para correspondência}

Etienne Andrade de Medeiros Dantas

Av. Petra Kelly, 61 Cond. Geraldo Galvão, Casa 45, Nova Parnamirim, CEP 59152330, Parnamirim-RN, Brasil

Endereço eletrônico: etienne.medeiros@gmail.com

Livia de Oliveira Borges

UFMG/FAFICH/Psicologia

Av. Antonio Carlos, 6627, SI. 4100 , Pampulha, CEP 31270-910, Belo Horizonte MG, Brasil

Endereço eletrônico: liviadeoliveira@gmail.com 
Etienne Andrade de Medeiros Dantas, Livia de Oliveira Borges Saúde Organizacional e Síndrome de Burnout em escolas e hospitais

Recebido em: 27/07/2010

Reformulado em: 11/01/2011

Aceito para publicação em: 24/01/2011

Acompanhamento do processo editorial: Deise Mancebo

\section{Notas}

* Doutoranda em em Psicologia - UFRN.

**Doutora em Psicologia com estágio pós-doutoral pela Universidade Complutense de Madri.

${ }^{1}$ Sobre o assunto sugere-se consultar publicações, como: Gorz (1982; 1980; 1991); Oliveira (1998); Leite (1994); Antunes (1995; 1999); Mattoso (1995); Castillo (1999); Castells (1999); Alaluf (2005).

${ }^{2}$ As leituras recomendadas na nota anterior são válidas, mas aqui se acrescentam e se destacam: Leite (1994); Ransome (1996); Castillo (1998); Blanch (2003); Toni (2003), Tumolo (2003); Alaluf (2005), entre outros.

${ }^{3}$ Veja por exemplo: Coriat (1993); Heloani (1996); Clegg, Hardy e Nord (1998); Guimarães e Medeiros (2003); Pilati, (2003); Bastos, loila, Queiroz e Silva (2004).

${ }^{4}$ Recomenda-se consultar sobre o assunto, por exemplo: Stroebe e Stroebe (1995); Álvaro e Paez (1996); Baum \& Posluszny (1999); Ogden (1999); Seligman e Csikszentmihalyi (2000); Benavides, García e Ruiz-Frutos (2004).

${ }^{5}$ Veja sobre o campo de saúde mental e trabalho: Jaffe (1995); Lima (1996); Bücher (2003); Codo, Soratto e Menezes (2004); Tamayo (2004); Sato, Lacaz e Bernardo (2006); Barbosa e Borges, (2007); Borges, Barbosa, Chaves e Andrade (2007). 